\title{
Variations in infant and childhood vitamin D supplementation programmes across Europe and factors influencing adherence
}

\author{
Suma Uday', Ardita Kongjonaj², Magda Aguiar ${ }^{3}$, Ted Tulchinsky ${ }^{4}$ and \\ Wolfgang Högler ${ }^{1,5}$
}

${ }^{1}$ Department of Endocrinology and Diabetes, Birmingham Children's Hospital, Birmingham, UK ${ }^{2}$ MEAL Specialist at Save the Children International, Albania Country Office, Tirana, Albania ${ }^{3}$ Health Economics Unit, University of Birmingham, Birmingham, UK

${ }^{4}$ Braun School of Public Health and Community Medicine, and Ashkelon College, Ashkelon, Israel

${ }^{5}$ Institute of Metabolism and Systems Research, University of Birmingham, Birmingham, UK

Correspondence should be addressed to W Högler

Email

wolfgang.hogler@nhs.net

\begin{abstract}
Background: Nutritional rickets is a growing global public health concern despite existing prevention programmes and health policies. We aimed to compare infant and childhood vitamin D supplementation policies, implementation strategies and practices across Europe and explore factors influencing adherence.

Methods: European Society for Paediatric Endocrinology Bone and Growth Plate Working Group members and other specialists completed a questionnaire on countryspecific vitamin D supplementation policy and child health care programmes, socioeconomic factors, policy implementation strategies and adherence. Factors influencing adherence were assessed using Kendall's tau-b correlation coefficient. Results: Responses were received from 29 of 30 European countries (97\%). Ninety-six per cent had national policies for infant vitamin D supplementation. Supplements are commenced on day $1-5$ in $48 \%$ (14/29) of countries, day 6-21 in 48\% (14/29); only the UK (1/29) starts supplements at 6 months. Duration of supplementation varied widely (6 months to lifelong in at-risk populations). Good ( $\geq 80 \%$ of infants), moderate $(50-79 \%)$ and low adherence $(<50 \%)$ to supplements was reported by $59 \%(17 / 29), 31 \%$ (9/29) and $10 \%(3 / 29)$ of countries, respectively. UK reported lowest adherence (5-20\%). Factors significantly associated with good adherence were universal supplementation independent of feeding mode $(P=0.007)$, providing information at neonatal unit (NNU) discharge $(P=0.02)$, financial family support $(P=0.005)$; monitoring adherence at surveillance visits $(P=0.001)$ and the total number of factors adopted $(P<0.001)$. Conclusions: Good adherence to supplementation is a multi-task operation that works best when parents are informed at birth, all babies are supplemented, and adherence monitoring is incorporated into child health surveillance visits. Implementation strategies matter for delivering efficient prevention policies.
\end{abstract}

\author{
Key Words \\ - micronutrients \\ - supplementation \\ - fortification \\ - policy implementation \\ - Europe \\ - rickets
}

Endocrine Connections (2017) 6, 667-675

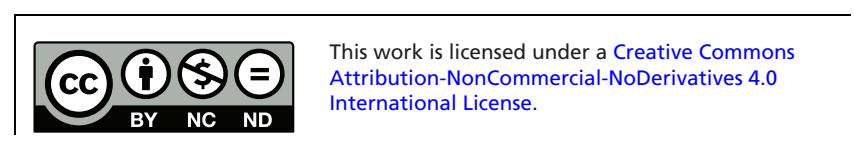




\section{Introduction}

Vitamin D deficiency and its complications such as osteomalacia, rickets, hypocalcaemic seizures, dilated cardiomyopathy and skeletal myopathy are a growing concern worldwide in high-, medium- and lowincome countries regardless of the geographic location $(1,2,3)$. If left untreated, long-term morbidity includes leg deformities, muscle weakness, falls and fractures, disability, unemployment and early death, such as from cardiomyopathy or obstructed labour. The cause and effect relationship between vitamin $\mathrm{D}$ and bone health is well established (4). Vitamin D supplementation of infants and pregnant mothers are practised in many countries to prevent rickets. The recent global consensus on the prevention of rickets recommends vitamin D supplementation not only during infancy and pregnancy but also for all ethnic risk groups (i.e. people with dark skin) especially those living at high latitude including all European countries $(2,5)$. In the wake of the European refugee crisis of 2015-2016, and the resulting longer term population demographic changes, Europe requires robust prevention programmes to protect the most vulnerable (6). However, there appears to be wide variation in the success of such vitamin D supplementation policies across Europe even for the existing population. We aimed to explore the differences in vitamin $\mathrm{D}$ policies and the factors relating to policy implementation that influence adherence rates.

\section{Methods}

A questionnaire with 20 questions was designed pertaining to the content of vitamin D supplementation policies, practices, infant health care and socioeconomic factors and policy implementation strategies. The questions were based on expert opinion (from paediatric endocrinology and public health) of factors that were perceived to influence adherence to infant vitamin D supplementation. The questions entailed:

- presence of a national policy and whether vitamin D supplementation was dependent on the mode of feeding;

- time of commencement and duration of supplementation;

- presence of a recommended number of child health surveillance visits, professionals providing care and prescribing vitamin D supplements;
- provision of financial family support and child care benefits by the government and whether supplements were free or paid for by the public;

- whether adherence to supplementation is systematically monitored at child health surveillance visits and measured as part of national statistics. In the absence of national statistics, experts were asked to provide adherence rates for the first year of life from local audits or estimates, and details on adherence problems in certain subgroups of the population;

- estimated average duration of breast feeding and time of weaning;

- report of national policies on food fortification with vitamin D.

The questionnaire was sent to members of the European Society of Paediatric Endocrinology (ESPE) Bone and Growth Plate Working Group in May 2014, which included representatives from Turkey, Israel and Russia. Additional effort was made, via various contacts and sources, to reach out to public health professionals and experts in the field in other European countries. Contacts were established with 30 countries and all except Iceland (97\%) responded. For countries with two respondents, responses to dichotomous variables (yes/no) were only included if they were consistent. For countries with more than 2 respondents, the response of the majority was considered in the final analysis, when there was inconsistency in response. When adherence was provided as an estimated range, the highest quoted rate was used for statistical analysis.

\section{Statistical analysis}

Descriptive statistics was used, and countries were ranked by adherence rate for the first year of life, as the main outcome. Countries were grouped into good $(\geq 80 \%$ of infants), moderate (50-79\%) and low adherence $(<50 \%)$. Adherence rate was cross tabulated with the total number of factors, and each individual factor, using Kendall's tau-b correlation coefficient in SPSS statistical software, version 22.0. The effect of individual factors and the total number of factors $(n=11)$ on estimated country-specific adherence rates was compared.

\section{Ethics}

The study did not involve patients, and therefore did not require ethical approval or consent. 


\section{Results}

Forty responses were received electronically from representatives of 29 European countries. Two responses were received from Poland, Portugal, Netherlands and Serbia, three from Spain and six from Germany.

\section{Characteristics of national policies}

All countries except Italy $(96 \%, 28 / 29)$ reported to have a national policy in place for vitamin D supplementation in infancy and childhood. Universal supplementation independent of the mode of feeding is recommended by $79 \%$ of countries (23/29), whereas only breastfed infants are supplemented in Italy, Russia, Serbia, Greece and the UK $(17 \%, 5 / 29)$.

\section{Commencement and duration of supplementation}

Vitamin D supplementation is commenced from day 1 to day 5 of life in $48 \%(14 / 29)$ and day 6 to day 21 in $48 \%(14 / 29)$ of European countries; the UK is the only country $(1 / 29)$ where supplements are not recommended until 6 months of life. The recommended duration of supplementation varied widely, ranging from a minimum of 6 months to lifelong in at-risk population (Supplementary Table 1, see section on supplementary data given at the end of this article).
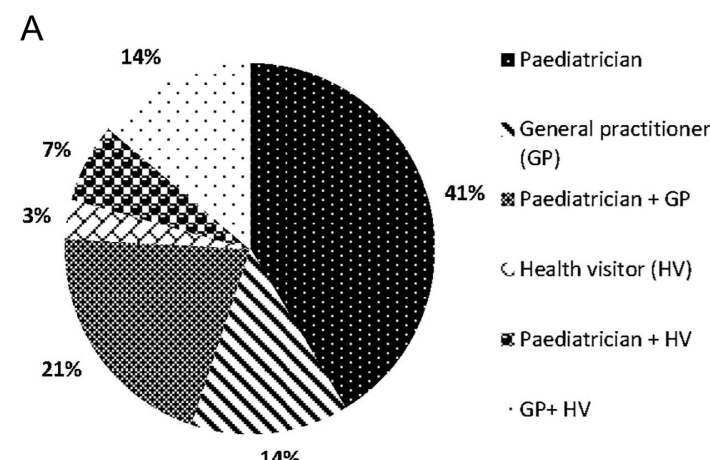

$14 \%$

\section{Professionals providing child health surveillance and prescribing vitamin supplements}

Information to new parents on the rationale for vitamin D supplementation is provided before discharge from the neonatal/delivery unit in $86 \%$ of countries $(24 / 28)$. Albania, Spain, Greece and the UK did not provide information to parents at discharge. Response from Portugal was not considered due to inconsistency.

All countries except Greece and Romania (93\% of countries) have a recommended number of child health surveillance visits usually associated with immunisation schedules ('red book' or passport programmes). The various professionals providing child health surveillance are illustrated in Fig. 1A. Paediatricians provide child health surveillance solely (41\%) or in partnership with other health care professionals (another 28\%).

The responsibility of prescribing vitamin $\mathrm{D}$ is with the paediatrician in most countries, either solely $(41 \%, 12 / 29)$ or in partnership with general practitioners $(24 \%, 7 / 29)$, as illustrated in Fig. 1B.

\section{Financial family support and child benefits}

Patients pay for their prescription in $62 \%$ of countries (18/29), whereas governments provide free vitamin D supplies in $28 \%(8 / 29)$. In Italy and the UK, only families on low income support receive free supplements, and in Norway, only people from ethnic minorities.

Financial family support for children is provided by $86 \%$ of countries $(25 / 29)$, varying from birth to a

\section{Figure 1}

Professionals responsible for providing child health surveillance $(A)$ and for prescribing vitamin $D$ supplements (B). (A) Child health surveillance is provided by paediatricians in $41 \%$ of countries (12/29), followed by a combination of a paediatrician and a general practitioner (GP) in $21 \%$ (6/29). In Romania, Ireland, Hungary and Sweden, GPs provide health surveillance (14\%, 4/29). Health visitors provide health surveillance in conjunction with: a Youth doctor in Netherlands, Paediatrician in Israel and GP in Denmark, Norway, Estonia and Finland (14\%, 4/29). The UK is the only country where health surveillance is provided solely by health visitors. (B) Vitamin D supplements are prescribed by the paediatrician in majority of the countries followed by a combination of paediatrician and general practitioner (GP). In Denmark, vitamin D is prescribed by the health visitor, in Sweden by the 'well baby clinic', in Israel by the 'Mother and Child Health centre', in Netherlands by the health visitor (HV) or 'Mother and Child Health centre'. Vitamins are not prescribed but available to buy over the counter in Finland and Ireland. In Estonia and Norway, vitamin D is prescribed by GP or HV, whereas in Lithuania and Romania, it is prescribed by the GP.

http://www.endocrineconnections.org $\quad$ C 2017 The authors
$\begin{array}{ll}\text { DOI: } 10.1530 / E C-17-0193 & \text { Published by Bioscientifica Ltd }\end{array}$

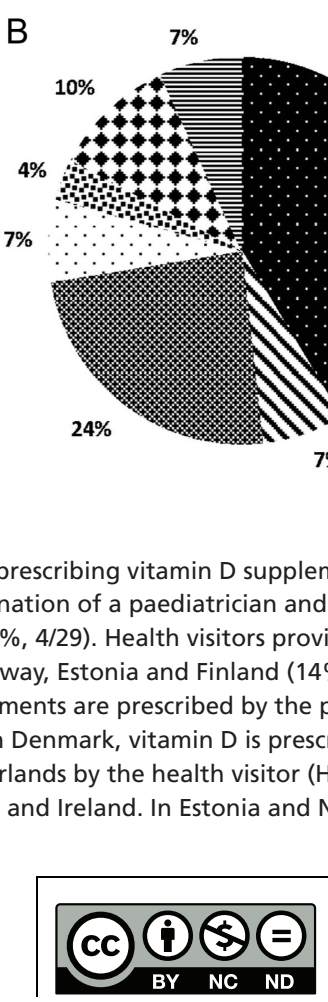

This work is licensed under a Creative Commons Attribution-NonCommercial-NoDerivatives 4.0 International License. 


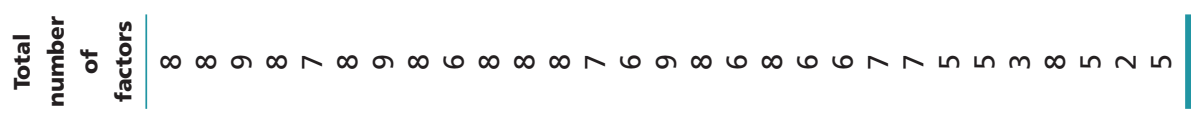
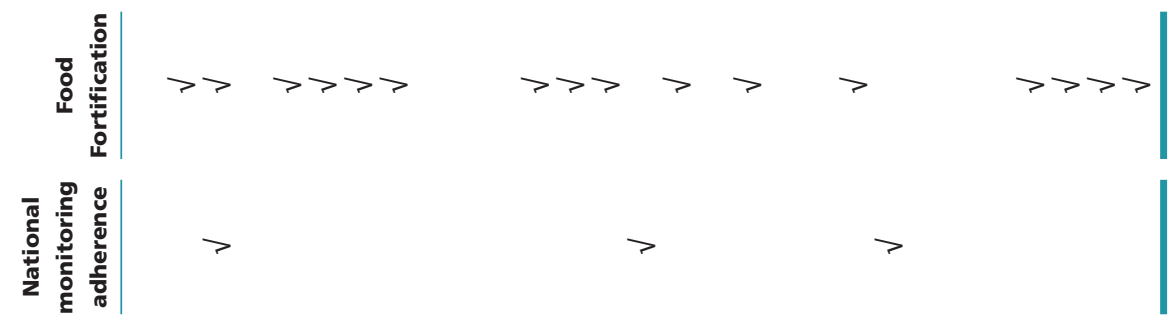

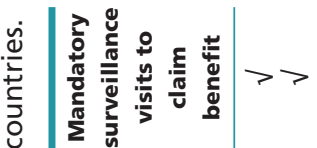
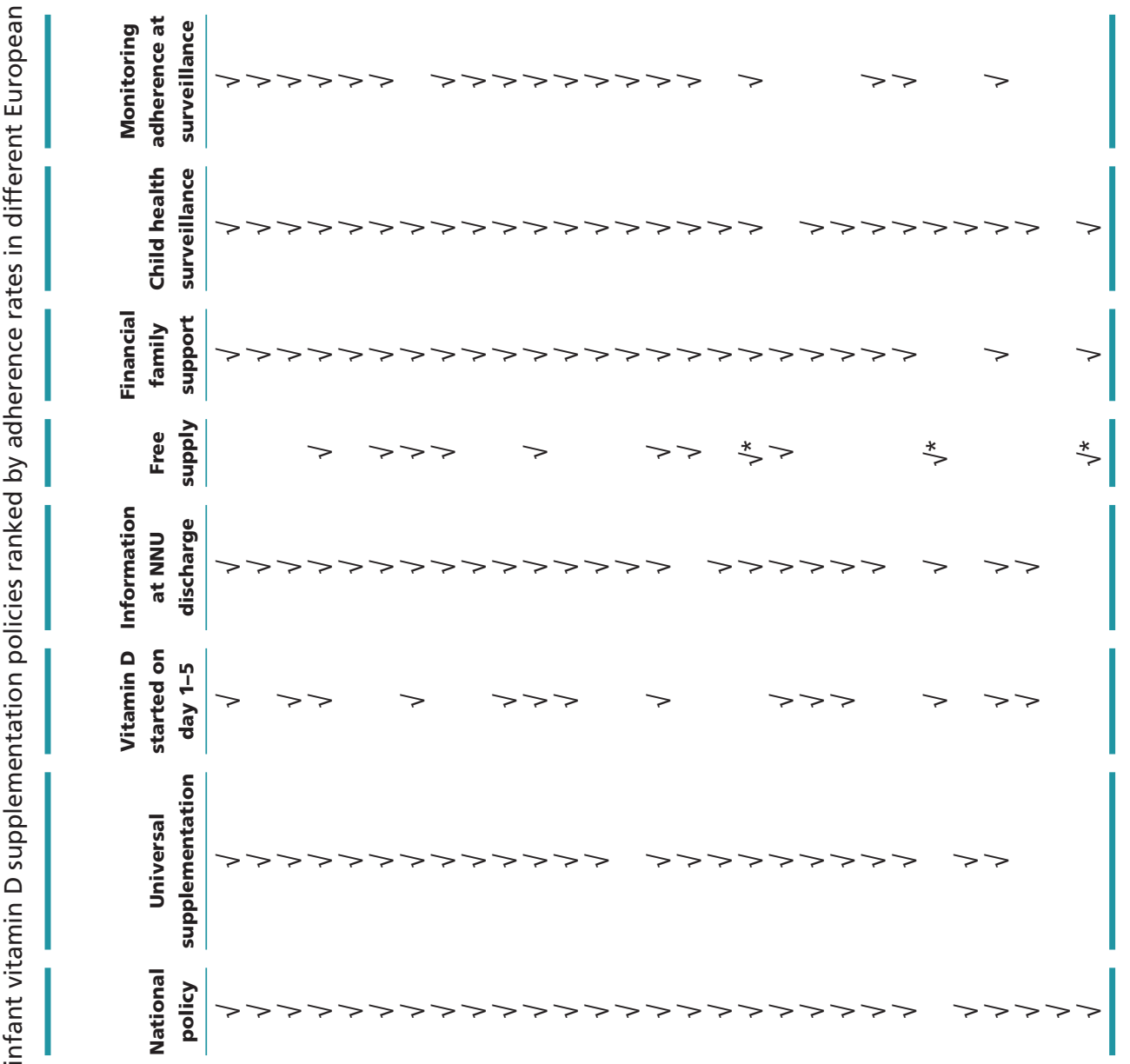

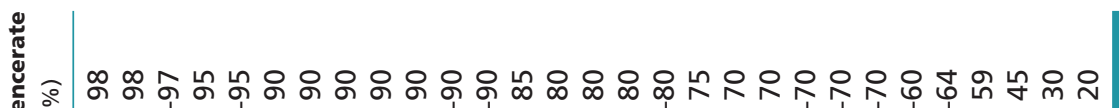
के

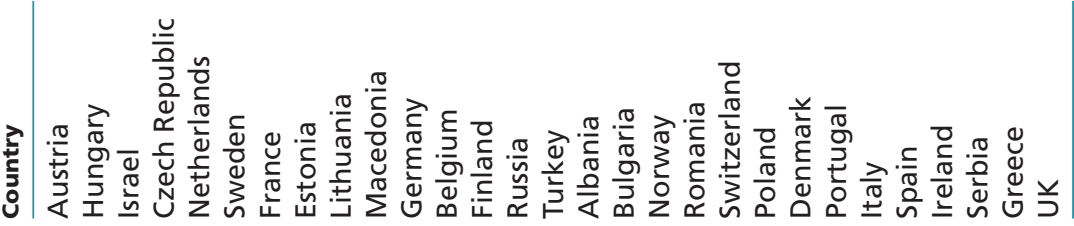


minimum of 26 weeks and a maximum of 18 years; however, only $28 \%$ of countries (7/25) - Albania, Austria, Bulgaria, France, Hungary, Italy and Macedonia - expect a $100 \%$ attendance at child health surveillance visits to be eligible to claim these benefits.

\section{Adherence and monitoring}

All countries reported an adherence rate to infant vitamin D supplementation in the first year of life. Denmark, Turkey and Israel (11\%) were the only countries that monitored adherence as part of national statistics. Germany, Ireland, Norway, Spain and UK provided evidence from regional studies. Estonia and Italy specified that the estimates were personal opinions and the remaining countries (19/29) did not specify the source of information and were assumed to be subjective estimates. Countries are ranked by adherence in Table 1 and depicted in Fig. 2. Good adherence ( $\geq 80 \%$ of infants) was reported by $59 \%$ of countries (17/29), moderate adherence (50-79\%) by 31\% (9/29) and low adherence $(<50 \%)$ by $10 \%$ of countries $(3 / 29)$. The UK had, by far, the lowest adherence rate (5-20\%). Poor adherence in specific population subgroups was reported by $46 \%(13 / 28)$ of countries; however, subgroups were named only by 6 countries. Bulgaria, Norway, Romania, Serbia, Sweden and Switzerland specified compliance issues in Romani communities, 'non-Westerners', the rural population, immigrants, low socioeconomic groups and protestant sects, respectively.

Arecommended number of child health surveillancevisits for ongoing assessment of a child's growth and development are practised in 93\% (27/29) of European countries; however, only $67 \%(18 / 27)$ incorporate a monitoring check for adherence to vitamin D supplementation.

\section{Infant feeding and food fortification}

Breast feeding was estimated to be practised by $>70 \%$ of mothers at 3 months and $>50 \%$ at 6 months in $41 \%$ $(12 / 29)$ of countries. Fewer women are breastfeeding in the other $59 \%$ of countries $(17 / 29)-10-70 \%$ of mothers at 3 months and $10-50 \%$ at 6 months.

Weaning is recommended at 6 months in $48 \%$ of countries (13/28) and 4 months in $25 \%$ of countries $(7 / 28)$. The recommendations varied between 4 months and 6 months in $25 \%$ of countries (7/28), mostly depending on the mode of feeding. Estonia recommended weaning at 4 months for vegetables and 6 months for meat.

Voluntary fortification of foods, other than infant formula, with vitamin D is practised in 55\% of countries $(16 / 29)$. No European country, except Israel currently mandates fortification. Fortified foods included milk,

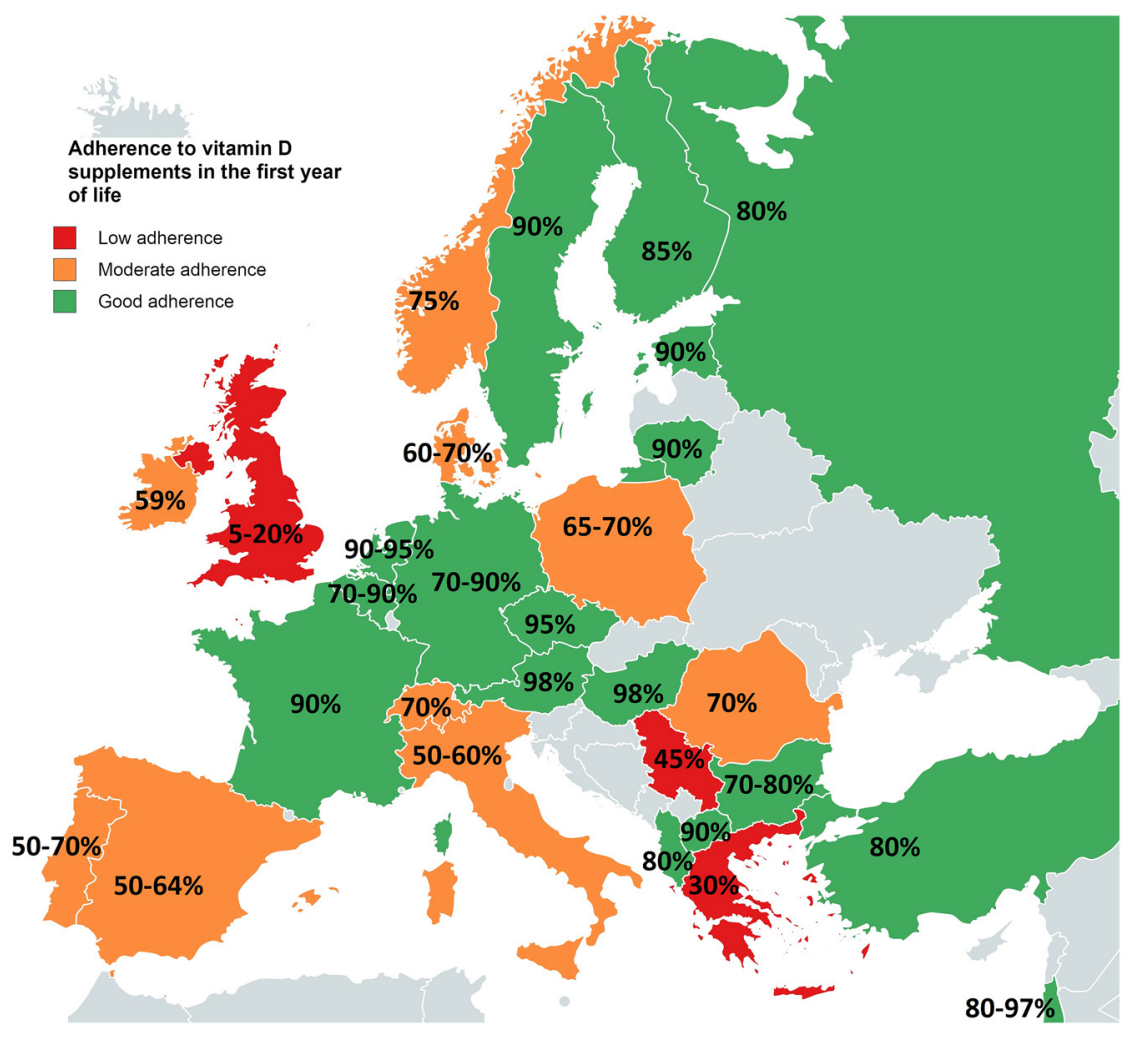

Figure 2

Adherence rates for infant vitamin $D$ supplementation in the first year of life in Europe. In the absence of national statistics, the adherence rates given are subjective estimates by experts in the field. Good adherence $(\geq 80 \%$ of infants supplemented) is indicated in green, moderate adherence (79-50\%) in orange and low adherence $(<50 \%)$ in red.

http://www.endocrineconnections.org DOI: 10.1530/EC-17-0193
() 2017 The authors Published by Bioscientifica Ltd This work is licensed under a Creative Commons
Attribution-NonCommercial-NoDerivatives 4.0 International License. 
margarine, yogurt, butter, dairy products, breakfast cereals, baby food and cookies.

\section{Factors influencing adherence}

Factors significantly associated with good adherence were universal supplementation independent of the mode of feeding $(P=0.007)$, providing information on supplementation at discharge from neonatal units (NNU) $(P=0.02)$, availability of financial family support $(P=0.005)$, monitoring of adherence to supplementation at child health surveillance visits $(P=0.001)$ and the total number of factors adopted $(P<0.001)$. Currently only $55 \%(16 / 29)$ of countries incorporate all the 4 significant individual factors.

The proportion of countries adopting each significant factor in the 3 adherence groups is illustrated in Fig. 3. Countries with good adherence fulfilled 6-9 (median 8) of the 11 factors listed in Table 1, whereas countries with moderate and low adherence fulfilled between 3 and 7 (median 6) and 2 and 5 (median 5) factors, respectively.

Factors not significantly associated with adherence rate included: Presence of national vitamin D supplementation policy $(P=0.4)$, commencement of supplements on day $1-5(P=1.0)$, free vitamin D supply by the government $(P=0.7)$, having a recommended number of child health surveillance visits $(P=0.07)$, mandatory attendance at surveillance visits to claim benefits $(P=0.1)$, national monitoring of adherence to supplementation $(P=0.8)$ and fortification of food with vitamin $\mathrm{D}(P=1.0)$.

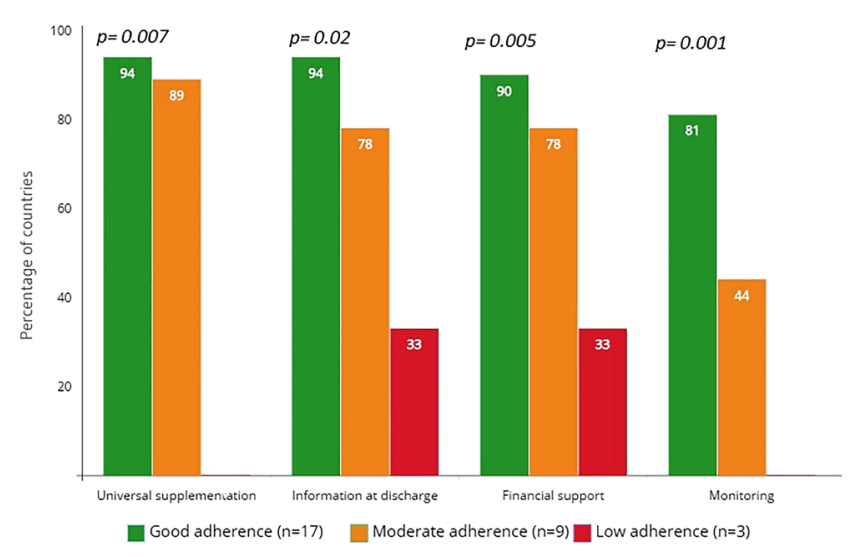

Figure 3

Percentage of countries adopting each of the 4 independent significant factors, per adherence groups: good $\geq 80 \%$, moderate $50-79 \%$ and low $<50 \%$ of infants supplemented during the first year of life.

\section{Discussion}

This survey demonstrates that vitamin D supplementation policies, their implementation strategies and adherence vary widely across Europe. Our study shows that universal vitamin D supplementation independent of the mode of feeding, providing information on supplementation at discharge from NNU, monitoring of adherence at recommended child health surveillance visits and availability of financial family support are policy features and implementation strategies associated with good adherence. Adherence improved as the total number of factors adopted increased. Other factors, such as the cultural acceptance of supplements by different ethnic groups were reported, but could not be sufficiently explored.

Universal supplementation from early life ( $<21$ days of life) is currently practised by $83 \%$ (24/29) of European countries. Vitamin D in infant formula is insufficient to protect infants from developing rickets (7). Hence, the global consensus on the prevention of rickets $(2,3)$ recommends $400 \mathrm{IU} /$ day $(10 \mu \mathrm{g})$ of vitamin $\mathrm{D}$ from birth to a minimum of 12 months of age, independent of the mode of feeding. This recommendation is also supported by our results, demonstrating that universal supplementation is associated with good adherence. Since vitamin D deficiency in the mother is always passed on to the infant, and serum half-life of 25-hydroxy vitamin D (25OHD) is only 2 weeks, prevention of rickets must include supplementation of pregnant women and infants from birth $(2,3)$. In the UK, supplements are not commenced until 6 months of age, which contributes to the rising incidence of rickets $(8,9)$, the morbidity from hypocalcaemic seizures (10), the deaths from hypocalcaemic cardiomyopathy (11) and undiagnosed rickets found post-mortem after unexplained sudden infant deaths reported in this country $(12,13)$. Notably, the vast majority of infants in these UK studies were from dark-skinned ethnic origin and fully breastfed. This study demonstrates that providing information at discharge from NNU and monitoring supplementation during health surveillance visits were associated with good adherence. Providing information and monitoring will automatically alert parents to the necessity of supplementation. Despite 93\% (27/29) of countries having a recommended number of child health surveillance visits, only 70\% (19/27) of these countries monitor adherence to vitamin D supplementation programme at these visits. A survey from the United Kingdom has demonstrated that $85 \%$ of parents are unaware of the need for infant vitamin D supplementation (14) possibly due to lack of monitoring and lack of information at discharge from NNUs. Ultimately, for supplementation policies to This work is licensed under a Creative Commons
Attribution-NonCommercial-NoDerivatives 4.0 International License. 
work, health care professionals should be responsible for prescribing and monitoring, which is best done alongside recommended health surveillance visits and immunisation schedules and documented in the personal child health record ('red book' or passport). Similarly, supplementation during pregnancy can be easily monitored during routine visits using the antenatal health record or passports.

Financial family support significantly enhanced adherence and should therefore be incorporated into policies where feasible. Whilst strict implementation of a free, monitored vitamin D supplementation programme reduced the prevalence of rickets in Turkey (15), this study found that free, unmonitored vitamin D supply in isolation did not increase adherence, a finding supported by the low uptake of 'Healthy Start' free vitamins in the UK (16). Although promotion campaigns reportedly reduce the incidence of symptomatic vitamin D deficiency $(17,18)$, monitoring of supplementation at recommended health surveillance visits is a more sustainable and systematic way of ensuring awareness and adherence, according to this study. We also demonstrate that policy implementation is a multi-task operation. The more factors incorporated into policies, the greater the adherence.

High-risk populations (reduced sunlight exposure due to geographic location, covered clothing, dark skin, institutionalisation or hospitalisation andlowsocioeconomic status, reduced dietary calcium intake) should receive vitamin $\mathrm{D}$ supplementation beyond 12 months of age $(2,3)$, which is currently not universally practised in Europe. The incidence of rickets (5) and prevalence of symptomatic $(19,20,21,22)$ and simple vitamin D deficiency in Europe (23) is several folds higher in dark-skinned (resident or immigrant) ethnic subgroups compared to white children. Ethnic minority and immigrant children remain at increased risk of symptomatic vitamin D deficiency beyond the recommended age of supplementation as demonstrated in the UK $(22,24)$ and Denmark $(25)$. These countries have changed their policies recommending lifelong supplementation in risk groups $(25,26)$. Similarly, the high prevalence of undiagnosed osteomalacia in adults related to vitamin D deficiency (27) highlights the importance of lifelong supplementation in the high-risk population. In light of the migration of dark-skinned people into Europe, there is an urgent need to review vitamin D supplementation policies and their implementation. Increased incidence of rickets in the immigrant population has been attributed not only to dark skin pigmentation, sun avoidance, covering the skin, but also to low dietary calcium intake (5). Of note, Norway and Sweden reported poor adherence in the immigrant population, and Romania and Serbia in those with low socioeconomic status, a known risk factor for poor adherence (28). Public health policies should therefore provide monitored, universal supplementation of all infants and these risk groups (dark-skinned, low socio economic status).

Food fortification of appropriate foods in conjunction with supplementation is most effective in preventing vitamin $\mathrm{D}$ deficiency by increasing population serum 25OHD levels (29) as seen in Canada (30). The majority of European countries in this study follow voluntary fortification, as noted before (31), and countries tend to fortify milk and milk products. Limiting fortification to one food type may put certain groups at risk (32); therefore, it is essential to consider dietary habits of at-risk populations and target fortification accordingly (33).

Vitamin D status in children is poorly studied across the globe (34). Paucity of national data on adherence to prevention programmes, as highlighted here, creates challenges in designing and comparing prevention policies. Policy makers should consider a central European database, which holds information on health policies to enable information retrieval and update. The European micronutrient recommendations aligned (EURRECA) project, established to address differences between countries in micronutrient recommendations, may be the right platform (35). Availability of accurate statistics on adherence will provide more robust evidence required to influence legislative authorities. In addition, investing in the prevention of vitamin D deficiency seems to have significant economic benefits $(36,37,38)$.

The main study limitation was that information on adherence, feeding practices and non-adherent groups was mainly based on expert opinions. In addition, some inconsistent responses where noted when there was more than one respondent, which may reflect regional differences within countries. However, in the absence of national data, estimation by experts in the field was the next best alternative. Data from 22 European countries were missing because no contact could be established. Nonetheless, the largest western and central European countries are represented (55\%), with different cultural and economic backgrounds.

\section{Conclusion}

The rise in nutritional rickets and low adherence to vitamin D supplementation are major public health concerns. Whilst national supplementation policies are in place across Europe, their implementation has been somewhat neglected. The results of this survey demonstrate that

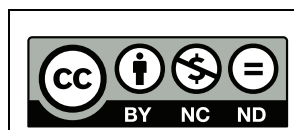

This work is licensed under a Creative Commons Attribution-NonCommercial-NoDerivatives 4.0 International License. 
relatively simple implementation strategies are associated with good adherence. Apart from providing information at discharge from NNU and universal supplementation of all babies, independent of the mode of feeding, the results of this survey specifically suggest that integrating the monitoring of adherence to supplementation into existing prevention programmes such as the child health surveillance visits ('red book', passports) increases adherence. Providing financial family support also enhanced adherence, suggesting that incentivising parents can improve child health. Improving adherence is a multi-task operation and one should adopt as many factors as feasible. Low and moderate adherence countries should consider adopting successful implementation strategies from high adherence European countries.

We call for more political effort to invest in implementation of efficient supplementation and fortification programmes to prevent symptomatic vitamin $\mathrm{D}$ deficiency, and thereby protect the most vulnerable members of society and minimise inequalities among socioeconomic groups and ethnic minorities.

\section{Key points:}

- All infants, pregnant women and risk groups should receive preventative vitamin $\mathrm{D}$ supplements.

- Supplementation policies are failing due to lack of clear implementation strategies and responsibilities.

- 59\% of European countries have good adherence to supplementation during the first year of life. Adherence to supplementation in the UK is lowest in Europe.

- Monitoring adherence at child health surveillance visits, providing universal supplementation, information at birth and financial family support are factors significantly associated with good adherence.

- A policy is only as good as its implementation strategy. Low and moderate adherence countries should consider adopting successful implementation strategies from high adherence European countries.

\section{Supplementary data}

This is linked to the online version of the paper at http://dx.doi.org/10.1530/ EC-17-0193.

\section{Declaration of interest}

The authors declare that there is no conflict of interest that could be perceived as prejudicing the impartiality of the research reported.

\section{Author contribution statement}

S U: Acquisition, analysis and interpretation of data. Draft and critical revision of manuscript. A K: Acquisition of data. T T: Critical contribution from public health perspective. M A: Contribution from public health economic perspective. $\mathrm{W} \mathrm{H}$ : Conception, design and data acquisition. Critical revision for intellectual content and final approval of manuscript.

\section{Funding}

This research did not receive any specific grant from any funding agency in the public, commercial or not-for-profit sector.

\section{Acknowledgement}

The authors would like to thank Peter Nightingale, statistician, University Hospital Birmingham, for excellent statistical support.

\section{Collaborators}

The authors would like to thank all the clinicians and contributors who kindly completed the questionnaire: Gabriele Haeusler, Hans-Georg Zmierczak, Maia Konstantinova, Zdeněk Šumník, Henrik Thybo Christesen \& Signe Beck-Nielsen, Vallo Tillmann, Outi Mäkitie, Agnès Linglart, Olaf Hiort, Susanne Bechtold-Dalla Pozza,Eckhard Schönau, Christine Hofmann, Dirk Schnabel \& Hermann Girschick, Artemis Doulgeraki, Anna Körner, Ciara McDonnell, Lisa Rubin, Giampiero Baroncelli, Robertas Kemezys, Dance Nikovska, Wilma Oostdijk, Annemieke Boot, Robert Bjerknes, Agnieszka Rusińska, Pawel Pludowski, Alice Mirante, Luminita Beldean, Mikhail Kostik, Maria Glibetic \& Maja Kristic, Diego De Sotto, José Miguel Sánchez Muro, Gabriel Ángel Martos Moreno, Lars Sävendahl, Marco Janner, Serap Turan \& Abdullah Bereket, Nick Shaw \& Eleanor McGee.

\section{References}

1 Holick MF. Vitamin D deficiency. New England Journal of Medicine $2007357266-281$.

2 Munns CF, Shaw N, Kiely M, Specker BL, Thacher TD, Ozono K, Michigami T, Tiosano D, Mughal MZ, Mäkitie O, et al. Global consensus recommendations on prevention and management of nutritional rickets. Hormone Research in Paediatrics 201585 83-106. (doi:10.1159/000443136)

3 Munns CF, Shaw N, Kiely M, Specker BL, Thacher TD, Ozono K, Michigami T, Tiosano D, Mughal MZ, Mäkitie O, et al. Global consensus recommendations on prevention and management of nutritional rickets. Journal of Clinical Endocrinology and Metabolism 2016101 394-415. (doi:10.1210/jc.2015-2175)

4 EFSA Panel on Dietetic Products, Nutrition and Allergies. Scientific opinion on the substantiation of a health claim related to vitamin D and contribution to normal bone and tooth development pursuant to Article 14 of Regulation (EC) No 1924/2006. EFSA Journal 201412 3579. (doi:10.2903/j.efsa.2014.3579)

5 Thacher TD, Pludowski P, Shaw NJ, Mughal MZ, Munns CF \& Högler W. Nutritional rickets in immigrant and refugee children. Public Health Reviews 201637 1-10.

6 Högler W \& Munns CF. Rickets and osteomalacia: a call for action to protect immigrants and ethnic risk groups. Lancet Global Health 2016 4 e229-e230

7 Gross ML, Tenenbein M \& Sellers EAC. Severe vitamin D deficiency in 6 Canadian First Nation formula-fed infants. International Journal of Circumpolar Health 201372 20244. (doi:10.3402/ijch.v72i0.20244)

8 Goldacre M, Hall N \& Yeates DGR. Hospitalisation for children with rickets in England: a historical perspective. Lancet 2014383 597-598. (doi:10.1016/S0140-6736(14)60211-7) 
9 Callaghan AL, Moy RJ, Booth IW, Debelle G \& Shaw NJ. Incidence of symptomatic vitamin D deficiency. Archives of Disease in Childhood 200691 606-607. (doi:10.1136/adc.2006.095075)

10 Basatemur E \& Sutcliffe A. Incidence of hypocalcemic seizures due to vitamin D deficiency in children in the United Kingdom and Ireland. Journal of Clinical Endocrinology and Metabolism 2015100 E91-E95. (doi:10.1210/jc.2014-2773)

11 Maiya S, Sullivan I, Allgrove J, Yates R, Malone M, Brain C, Archer N, Mok Q, Daubeney P, Tulloh R, et al. Hypocalcaemia and vitamin D deficiency: an important, but preventable, cause of life-threatening infant heart failure. Heart 200894 581-584. (doi:10.1136/ hrt.2007.119792)

12 Scheimberg I \& Perry L. Does low vitamin D have a role in pediatric morbidity and mortality? An observational study of vitamin D in a cohort of 52 postmortem examinations. Pediatric and Developmental Pathology 201417 1-27.

13 Cohen MC, Offiah A, Sprigg A \& Al-Adnani M. Vitamin D deficiency and sudden unexpected death in infancy and childhood: a cohort study. Pediatric and Developmental Pathology 201316 292-300. (doi:10.2350/13-01-1293-OA.1)

14 Drury R, Rehm A, Johal S \& Nadler R. Vitamin D supplementation: we must not fail our children! Medicine 201594 e817. (doi:10.1097/ MD.0000000000000817)

15 Hatun Ş, Ozkan B \& Bereket A. Vitamin D deficiency and prevention: Turkish experience. Acta Paediatrica, International Journal of Paediatrics 2011100 1195-1199. (doi:10.1111/j.1651-2227.2011.02383.x)

16 Jessiman T, Cameron A, Wiggins M \& Lucas PJ. A qualitative study of uptake of free vitamins in England. Archives of Disease in Childhood 201398 587-591. (doi:10.1136/archdischild-2013-303838)

17 Moy RJ, McGee E, Debelle GD, Mather I \& Shaw NJ. Successful public health action to reduce the incidence of symptomatic vitamin D deficiency. Archives of Disease in Childhood 201297 952-954. (doi:10.1136/archdischild-2012-302287)

18 Dunnigan MG, McIntosh WB, Sutherland GR, Gardee R, Glekin B, Ford JA \& Robertson I. Policy for prevention of Asian rickets in Britain: a preliminary assessment of the Glasgow rickets campaign. BMJ 1981282 357-360. (doi:10.1136/bmj.282.6261.357)

19 Hintzpeter B, Scheidt-Nave C, Müller MJ, Schenk L \& Mensink GB. Higher prevalence of vitamin D deficiency is associated with immigrant background among children and adolescents in Germany. Journal of Nutrition 2008138 1482-1490.

20 Van Der Meer IM, Middelkoop BJC, Boeke AJP \& Lips P. Prevalence of vitamin D deficiency among Turkish, Moroccan, Indian and sub-Sahara African populations in Europe and their countries of origin: an overview. Osteoporosis International 201122 1009-1021. (doi:10.1007/s00198-010-1279-1)

21 Ford L, Graham V, Wall A \& Berg J. Vitamin D concentrations in an UK inner-city multicultural outpatient population. Annals of Clinical Biochemistry 200643 468-473. (doi:10.1258/000456306778 904614)

22 Ahmed SF, Franey C, McDevitt H, Somerville L, Butler S, Galloway P, Reynolds L, Shaikh MG \& Wallace AM. Recent trends and clinical features of childhood vitamin D deficiency presenting to a children's hospital in Glasgow. Archives of Disease in Childhood 201196 694-696. (doi:10.1136/adc.2009.173195)

23 Cadario F, Savastio S, Magnani C, Cena T, Pagliardini V, Bellomo G, Bagnati M, Vidali M, Pozzi E, Pamparana S, et al. High prevalence of vitamin D deficiency in native versus migrant mothers and newborns in the North of Italy: a call to act with a stronger prevention program. PLOS ONE 201510 e0129586.
24 Ladhani S, Srinivasan L, Buchanan C \& Allgrove J. Presentation of vitamin D deficiency. Archives of Disease in Childhood 200489 781-784. (doi:10.1136/adc.2003.031385)

25 Beck-Nielsen SS, Brock-Jacobsen B, Gram J, Brixen K \& Jensen TK. Incidence and prevalence of nutritional and hereditary rickets in southern Denmark. European Journal of Endocrinology 2009160 491-497. (doi:10.1530/EJE-08-0818)

26 Scientific Advisory Commitee on Nutrition. Vitamin $D$ and health. London, UK: Public Health England, 2016. (available at: https:// www.gov.uk/government/publications/sacn-vitamin-d-and-healthreport)

27 Priemel M, von Domarus C, Klatte TO, Kessler S, Schlie J, Meier S, Proksch N, Pastor F, Netter C, Streichert T, et al. Bone mineralization defects and vitamin D deficiency: histomorphometric analysis of iliac crest bone biopsies and circulating 25-hydroxyvitamin D in 675 patients. Journal of Bone and Mineral Research 201025 305-312. (doi:10.1359/jbmr.090728)

28 Novaković R, Cavelaars A, Geelen A, Nikolić M, Altaba II, Viñas BR, Ngo J, Golsorkhi M, Medina MW, Brzozowska A, et al. Socio-economic determinants of micronutrient intake and status in Europe: a systematic review. Public Health Nutrition 201417 1031-1045.

29 Black LJ, Seamans KM, Cashman KD \& Kiely M. An updated systematic review and meta-analysis of the efficacy of vitamin D food fortification. Journal of Nutrition 2012142 1102-1108. (doi:10.3945/ jn.112.158014)

30 Shakur YA, Lou W \& L'Abbe MR. Examining the effects of increased vitamin D fortification on dietary inadequacy in Canada. Canadian Journal of Public Health 2014105 e127-e132. (doi:10.17269/ cjph.105.4086)

31 Spiro A \& Buttriss JL. Vitamin D: an overview of vitamin D status and intake in Europe. Nutrition Bulletin 201439 322-350. (doi:10.1111/ nbu.12108)

32 Cashman KD \& Kiely M. Tackling inadequate vitamin D intakes within the population: fortification of dairy products with vitamin D may not be enough. Endocrine 201651 38-46. (doi:10.1007/s12020-015-0711-x)

33 Allen RE, Dangour AD, Tedstone AE \& Chalabi Z. Does fortification of staple foods improve vitamin D intakes and status of groups at risk of deficiency? A United Kingdom modeling study. American Journal of Clinical Nutrition 2015102 338-344. (doi:10.3945/ajcn.115.107409)

34 Wahl DA, Cooper C, Ebeling PR, Eggersdorfer M, Hilger J, Hoffmann K, Josse R, Kanis JA, Mithal A, Pierroz DD, et al. A global representation of vitamin D status in healthy populations. Archives of Osteoporosis 20127 155-172. (doi:10.1007/s11657-012-0093-0)

35 Doets EL, De Wit LS, Dhonukshe-Rutten RAM, Cavelaars AE, Raats MM, Timotijevic L, Brzozowska A, Wijnhoven TM, Pavlovic M, Totland TH, et al. Current micronutrient recommendations in Europe: towards understanding their differences and similarities. European Journal of Nutrition 200847 17-40. (doi:10.1007/s00394-008-1003-5)

36 McGee E. Prevention of Rickets and Vitamin D Deficiency in Birmingham: The Case for Universal Supplementation. Birmingham, UK: National Health Service, 2010.

37 Kamudoni P, Poole C \& Davies SJ. An estimate of the economic burden of vitamin D deficiency in pregnant women in the United Kingdom. Gynecological Endocrinology 20163590 1-6.

38 Filby A, Lewis L \& Taylor M. An Economic Evaluation of Interventions to Improve the Uptake of Vitamin D Supplements in England and Wales. PH56. London, UK: National Institute for Health and Care Excellence, 2014.

Received in final form 9 September 2017

Accepted 18 September 2017

Accepted Preprint published online 18 September 2017 http://www.endocrineconnections.org DOI: 10.1530/EC-17-0193 (c) 2017 The authors Published by Bioscientifica Ltd
This work is licensed under a Creative Commons Attribution-NonCommercial-NoDerivatives 4.0 International License. 